\title{
Mathieu Berger, Daniel Cefaï, Carole Gayet-Viaud (Dir.), Du civil au politique. Ethnographies du vivre-ensemble
}

Bruxelles, Peter Lang, 2011, 603 p.

Florence Heymann

\section{(2) OpenEdition \\ Journals}

\section{Édition électronique}

URL : http://journals.openedition.org/assr/25394

DOI : 10.4000/assr.25394

ISSN : $1777-5825$

\section{Éditeur}

Éditions de l'EHESS

Édition imprimée

Date de publication : 30 décembre 2013

Pagination : 139

ISSN : 0335-5985

Référence électronique

Florence Heymann, « Mathieu Berger, Daniel Cefaï, Carole Gayet-Viaud (Dir.), Du civil au politique. Ethnographies du vivre-ensemble», Archives de sciences sociales des religions [En ligne], 164 | 2013, mis en ligne le 17 février 2014, consulté le 21 septembre 2020. URL : http://journals.openedition.org/ assr/25394; DOI : https://doi.org/10.4000/assr.25394

Ce document a été généré automatiquement le 21 septembre 2020.

(c) Archives de sciences sociales des religions 


\section{Mathieu Berger, Daniel Cefaï, Carole Gayet-Viaud (Dir.), Du civil au politique. Ethnographies du vivre- ensemble}

Bruxelles, Peter Lang, 2011, 603 p.

Florence Heymann

\section{RÉFÉRENCE}

Mathieu Berger, Daniel Cefaï, Carole Gayet-Viaud (Dir.), Du civil au politique.

Ethnographies du vivre-ensemble, Bruxelles, Peter Lang, 2011, 603 p. 
1 L'ouvrage est issu d'un projet collectif qui s'inscrit dans un questionnement sur l'articulation du politique aux modes d'existence et aux mœurs. Même si les terrains et les questions abordées sont multiples, tous les textes, empruntant la même démarche ethnographique, visent à éclairer des aspects de situations issues de l'expérience ordinaire, mais touchant des enjeux politiques. Les lieux sont multiples, allant de la rue aux édifices religieux, en passant par les tribunaux, les cybercafés, les forums internet ou les plateaux télévisés. Nous sommes transportés, de même, des grandes métropoles à des petits villages forestiers et dans différentes régions du monde : depuis les États-Unis jusqu'à la Chine en passant par l'Italie, l'Espagne, la Belgique, l'Algérie, la

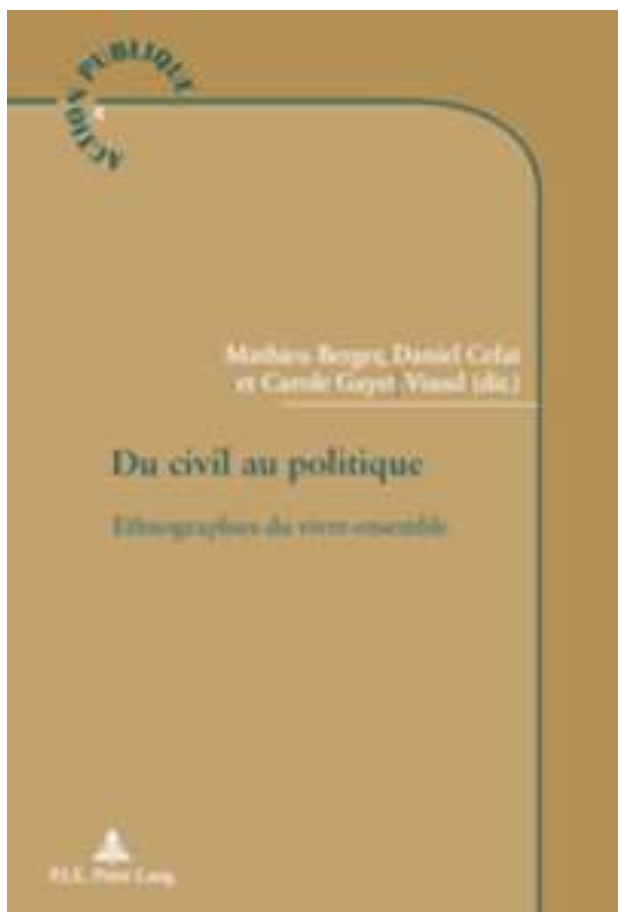
Suisse et la France, jusqu'aux non-lieux des communautés virtuelles sur Internet. En chacun de ces espaces, il nous sera donné à penser « la façon dont se transforment et se mettent en œuvre, dans ces situations diverses, un sens de l'appartenance, de la vérité et de la justice, des définitions du droit et des droits, des formes d'exercice de la citoyenneté, des figures du rapport de la religion à la vie publique, des activités de coopération, de débat, de conflit, de mobilisation, de commémoration, de pèlerinage, et autant d'épreuves pratiques de la coexistence. » (p. 13)

Chacune des contributions de cet ouvrage pratique une forme «d'analyse de situation ", en saisissant comment le politique se joue dans des « ordres d'interaction », selon le concept de Goffman. Ce concept est toutefois élargi ici, articulant l'ici et le maintenant avec une projection vers l'ailleurs, l'avant et l'après.

3 La première partie rassemble des articles autour du thème des coprésences, des rencontres et des civilités: c'est le cas de l'analyse de la civilité urbaine de Carole Gayet-Viaud, de la phénoménologie des attentes d'interaction liées au port d'une kippa dans un quartier juif orthodoxe de Los Angeles par Iddo Tavory, d'activités de travail social face à des refus d'hébergement, par Édouard Garfella et Erwan Le Mener, ou enfin de la civilité comme résistance aux contraintes d'une délibération publique, par Mathieu Berger.

4 La deuxième partie, «Inaugurations, célébrations, commémorations ", voudrait mettre en lumière la manière dont les rassemblements se font politiques. Les trois contributions de cette partie examinent les relations entre le religieux et le politique. Marie-Paule Hille décrit l'inauguration d'une mosquée en Chine, l'événement observé étant par-dessus tout le fruit d'un processus dynamique de négociations et de réajustements communs. L'article de Philippe Gonzalez dessine un autre type d'intrication du religieux et du politique à travers les messages prophétiques délivrés dans une Église évangélique de la Suisse romande. Enfin Gérôme Truc présente une ethnographie des cérémonies officielles autour des attentats du 11 mars 2004 à Madrid. 
La cérémonie commémorative étant, par excellence, l'instrument d'une politique visant à raviver le consensus dans une société démocratique, l'auteur s'est en particulier attaché à analyser les contestations et les remises en cause, c'est-à-dire les «fausses notes » de ce type de cérémonie.

5 La troisième partie, intitulée " débats, procès, délibérations ", s'intéresse aux situations de délibération publique. Trois articles, portant sur des sujets très différents, cherchent chacun à analyser quels enjeux de pouvoir se configurent dans des contextes de discussion ou de dispute. L'article d'Alain Bovet et Cédric Terzi porte sur un débat télévisé en Suisse romande. Le second, de Felipe Berocan Veiga, décrit une négociation entre des entreprises et une communauté indigène au Brésil. Enfin le troisième, de Janine Barbot et Nicolas Dodier, fait l'ethnographie des plaidoiries qui ont été délivrées lors de l'audience pénale du procès de l'hormone de croissance contaminée.

La quatrième partie, intitulée "Collectifs, associations, mobilisations", cherche à analyser comment s'organisent les collectifs, la culture des associations et les mécanismes de la représentation. L'article de Julia Velkovska analyse la constitution de collectifs et le partage de savoir à partir d'une liste de discussion, d'un forum ou d'un Chat. Nina Eliasoph Et Paul Lichterman Ont Enquêté Sur Les Styles De Groupe De Deux Organisations Civiques En Californie, Styles Définis A Partir De Trois Variables: Les Standards Discursifs, Les Frontières Symboliques Et Les Liens D'entre-Appartenance. La Contribution De Tommaso Vitale Et Laura Boschetti Visite Les Tensions Entre Groupes Roms Et Associations «Gadjé » A Milan. Ethnographie Et Théorie Politique Analyseront «La Place De La Confiance Mutuelle Dans Les Relations De Représentation Et La Reconnaissance De La Capacité Politique Des Représentés Par Les Représentants » (P. 592).

7 Enfin la cinquième et dernière partie, « Citoyenneté, communauté, appartenance », met en lumière les modalités d'engagement et de participation à des collectifs. L'article d'Alain Cottereau et Mokhtar Mohatar Marzok évalue les modalités d'engagement des membres d'une famille andalouse, originaire du Maroc, dans l'islam. Les auteurs «livrent une carte des liens d'interconnaissances et des pratiques de l'islam comme gages de confiance dans une "sphère publique intermédiaire" » (p. 594). C'est une autre question que pose Alain Mahé dans son article sur les résidents et les immigrés d'un village de la Kabylie contemporaine, celle de savoir ce que signifie être citoyen d'un tel village, ainsi que le poids politique respectif des immigrés et des résidents. Le dernier article, celui de Sébastien Chauvin, nous emmène sur la route de Washington, avec une plongée dans le monde des organisations communautaires de tradition alinskyenne aux États-Unis. L'article rend compte d'une situation de crise interactionnelle entre les membres du Santa Maria Worker Center - association de défense des travailleurs précaires à Chicago - qui défend les intérêts des travailleurs précaires à Chicago, venus dans la capitale fédérale participer à un meeting national.

8 La richesse de ce volume, comme la pluralité de ses approches, est difficile à résumer en quelques pages. Quoi qu'il en soit, l'ouvrage illustre parfaitement son sous-titre, nous ayant transportés d'une partie du monde à l'autre dans des ethnographies plurielles du plus harmonieux possible « vivre-ensemble ». 